\title{
Optical Properties for SeTe Thin Films
}

\author{
Salma M. Shaban*
}

Date of acceptance 20/7/2008

\begin{abstract}
:
Chalcogenide glasses SeTe have been prepared from the high purity constituent elements .Thin films of SeTe compound have been deposited by thermal evaporation onto glass substrates for different values of film thickness. The effect of varying thickness on the value of the optical gap is reported. The resultant films were in amorphous nature. The transmittance spectra was measured for that films in the wavelength range (400-1100) $\mathrm{nm}$. The energy gap for such films was determined .
\end{abstract}

\section{Introduction :}

Chalcogenides glasses have received much attention due to their most important applications in the field of optics and arise mainly from either their exhibited infrared transmitting properties or photo-induced effects $[1,2]$. It has been found that Se-alloys are useful because of its greater hardness, high photosensitivity ,higher crystallization temperature [3] The structure of the thin films strongly influences the electronic properties and is highly dependent upon the preparation technique and deposition conditions. The structure disorder in amorphous semiconductors have been much attention for the development of better, cheaper and more reliable solid state devices. Se-Te alloys have been found to be useful in practical applications ${ }^{[4]}$ and Technologically , these glasses should be thermally stable. The aim of the present work is to study some optical parameters like , transmission, absorption coefficient , and optical band gap. Also it have been studied the effect of the thickness on these parameters .

\section{Experimental :}

Thermal evaporation method is used for obtaining different thicknesses of amorphous SeTe thin films under vacuum $\left(1 \times 10^{-5}\right.$ torr $)$ onto cleaned glass substrates . The distance between the boat and the substrate is $10 \mathrm{~cm}$. A molybdenum boat was used. An Edwards E 306 A was used to deposit thin films. SeTe films were evaporated thermally with a deposit rate $0.5 \mathrm{~nm} / \mathrm{s}$ .The X-ray diffraction patterns exhibit no intense peaks that indicate these films are of amorphous nature . A Shimadzu model and uv-visible recorder spectrophotometer UV-160, is used to record the transmittance spectra over the wavelength rang (2001100) $\mathrm{nm}$.

\section{Results and Discussion :}

As shown in Fig. (1), the structure of films are of amorphous nature .

\footnotetext{
* Physics Department, College of Science, University of Baghdad
} 


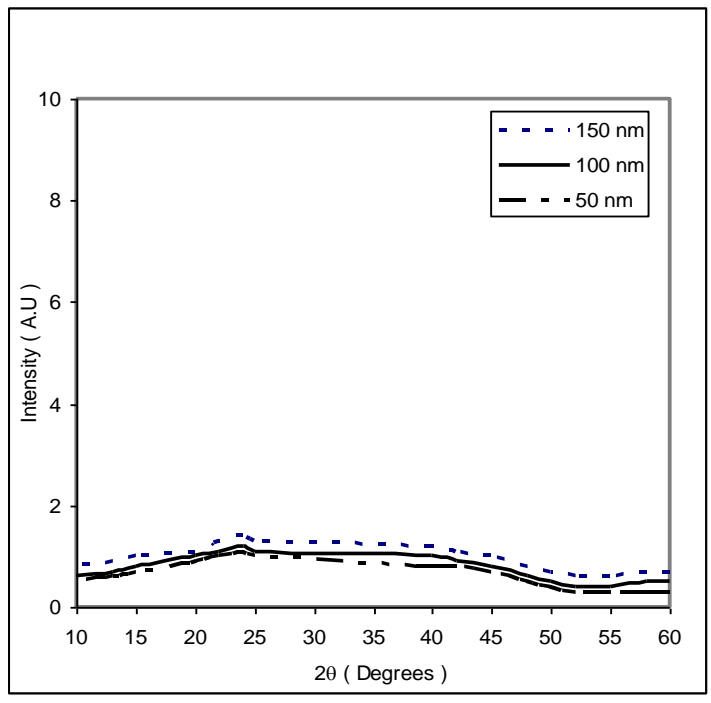

Fig.(1) X-ray diffraction of SeTe films

Fig. (2) Shows the transmittance spectra of SeTe amorphous thin films for thicknesses $(50,100,150) \mathrm{nm}$. We indicate from the figure that with the increase of film thickness, there is a shift in transmittance toward regions of shorter wavelength. The shift may be influenced by the superposition degree of the electron clouds of the neighboring atoms, which consequently affect the optical band gap width.

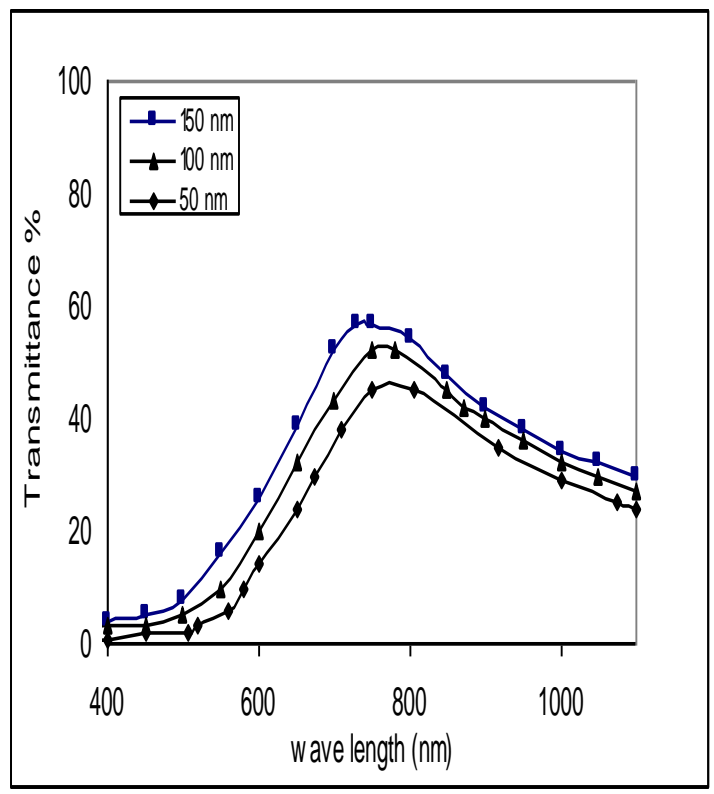

Fig.(2) Transmittance spectra of SeTe films .
The optical absorption coefficient, $\alpha$, is related to the transmittance of a film with thickness, $\mathrm{d}$, through the relation [5]

$\alpha=(2.303 / \mathrm{d}) \log (1 / \mathrm{T})$

According to reference ${ }^{[6]}$, there are three distinct regions in the absorption edge spectrum of amorphous semiconductor, the first is the weak absorption tail, which originates from defects and impurities .The second is the exponential edge region which is strongly related to the structural randomness of the amorphous compound, and the third is the high absorption region from which optical energy gap width can be determined .The above three absorption regions can easily observed in Fig (3), where the first region (from 750 to 1100 ) nm, the second (from 500 to 700 ) $\mathrm{nm}$, and the third (approximately at $400 \mathrm{~nm}$ ) . So these regions are different in their beginnings and endings for the different thicknesses under investigations .

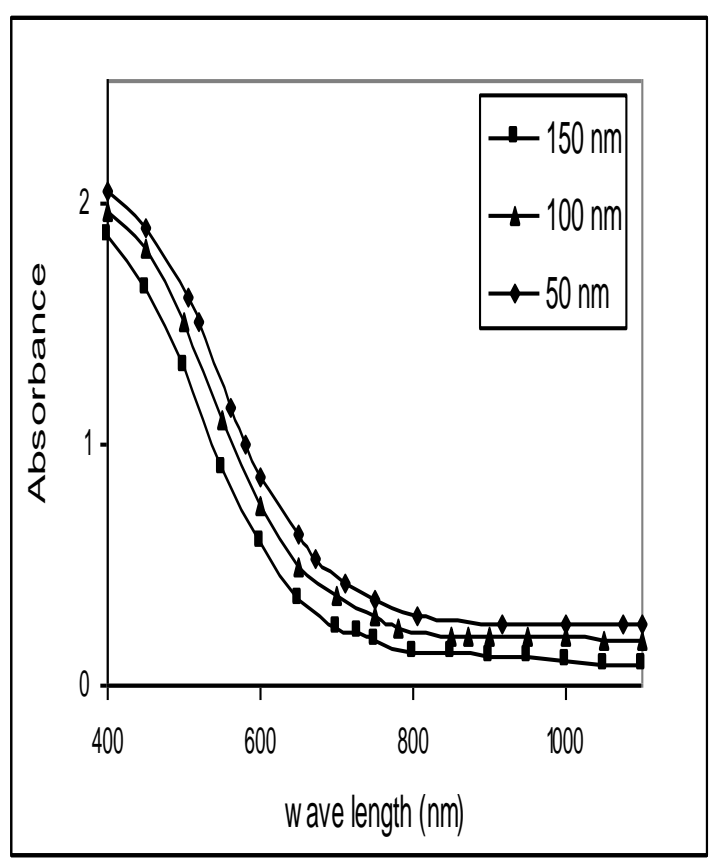

Fig(3) Absorbance spectra of SeTe flms . 
In the high absorption regions, the relationship between the absorption coefficient and the incident photon energy is governed by the relation ${ }^{[5]}$

$\alpha(\mathrm{h} v)=\mathrm{A}(\mathrm{h} v-\mathrm{Eg})^{\mathrm{n}}$

Where A is constant, Eg is the width of the bond gap, and $\mathrm{n}$ is an index that characterizes the optical absorption processes .In the present study, the dominant transition is direct allowed and $n=1 / 2$. A plot of $(\alpha h y)^{2}$ as a function of hy is shown in Fig.(4) .

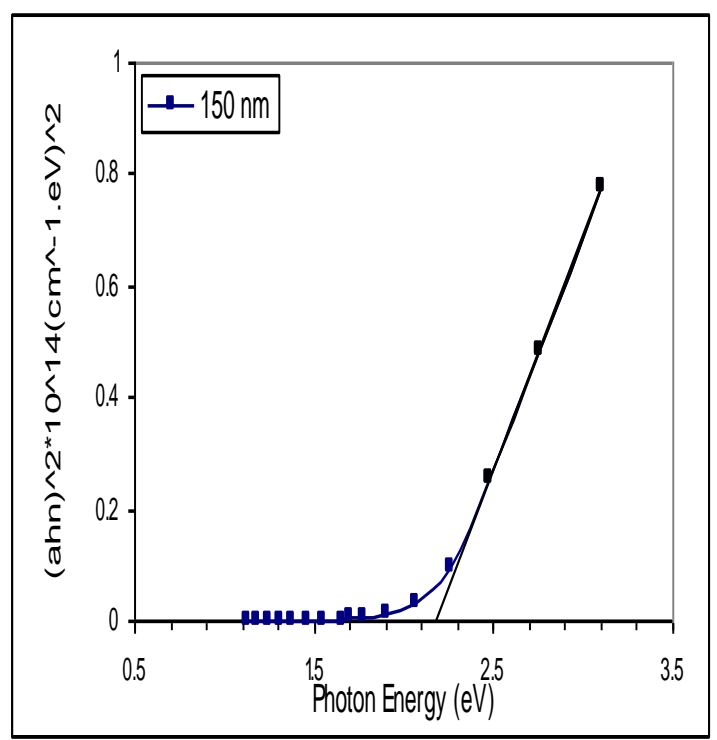

( a )

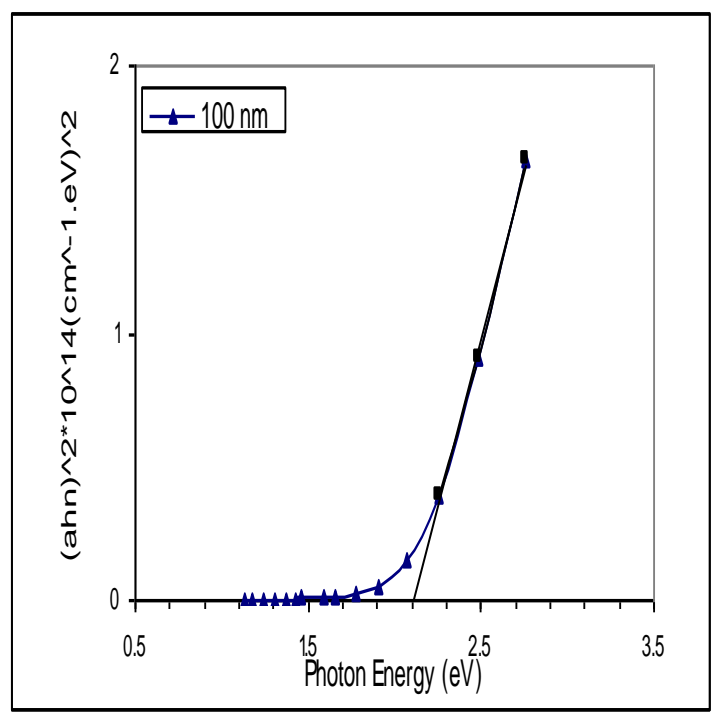

( b )

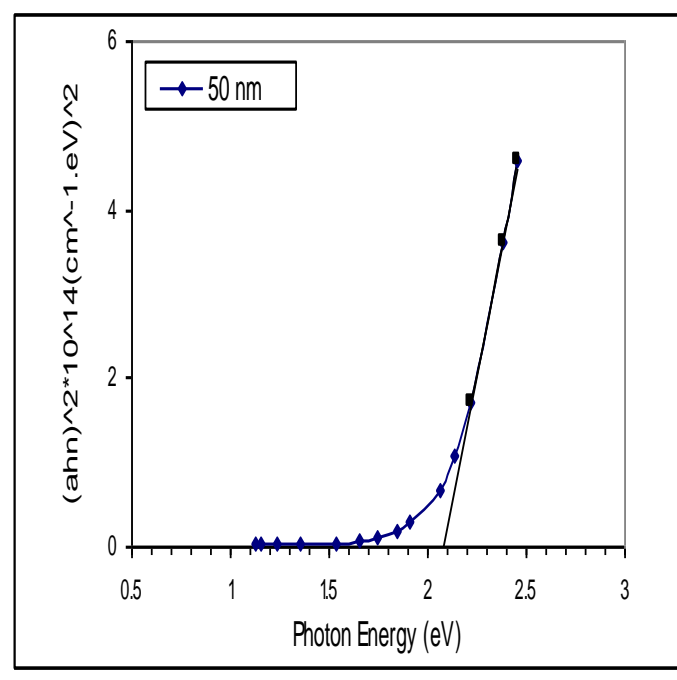

(c)

Fig.(4) Plot of (ahy $)^{2}$ as a function of (hy) for various thicknesses ( $a=150$ $n m, b=100 \mathrm{~nm}, c=50 \mathrm{~nm})$.

From Fig . (4), the optical band gap were calculated by linear fitting in the high absorption regions. These fits intersect the hy-axis at the values of the optical band dap widths , and show that the direct allowed band gap width of the amorphous SeTe thin films increases with the increase in the film thickness which returns to the improved structure of the films, as indicated in Table (1). This result is in agreement with chernyaer ${ }^{[7]}$ for his study of optical properties on SnTe compound .

Table (1)

The optical energy gap of SeTe thin films

\begin{tabular}{|c|c|}
\hline $\begin{array}{c}\text { Thickness } \\
(\mathbf{n m})\end{array}$ & $\begin{array}{c}\text { Energy gap } \\
(\mathbf{e V})\end{array}$ \\
\hline 50 & 2.08 \\
\hline 100 & 2.1 \\
\hline 150 & 2.18 \\
\hline
\end{tabular}




\section{Conclusion :}

In the transmittance spectra, the transmission of the films shifs toward the shorter wavelength with the increase of film thickness. It was found that, for amorphous SeTe thin films with different thicknesses, the optical energy gap increases with increasing film thickness. The transition type in amorphous SeTe films exhibit direct allowed .

\section{References :}

1. Hilton A. R., Hayes D . J. and Beehitin M. D., 1975 . J. Non cryst . solids . 17 (2): 319 .
2. Sanghara J. S. and Agarwal I. D. ,1999 . J. Non - cryst. Solids . 6 (4) : 256 .

3. KushwahaV.S.,2005.Turkish J. Phys.. 29 (5) : 349 .

4. Singh S.P., 2004. J. Mat.. Sci.. 39 (2) $: 1$.

5. Tauc. J . , 1974 .Amorphous and liquid semiconductors. New York, Plenum : ch. 4 , pp155 .

6. Pankove J. I. , 1971. Optical Processes in Semiconductors . New Jersey , Prentice - Hall , pp.93 .

7. chernyaer V. N. and Korzo V. F. , 1976. Thin Solid Films .37 (6) : L61 .

\section{الخصائص البصرية لآغشية SeTe الرقيقة}

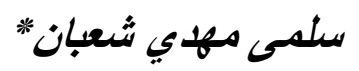

* قسم الفيزياء / كلية العلوم / جامعة بغداد

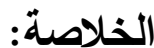

حضرت الجالكوجينات الزجاجية SeTe من العناصر Se,Te ذات نقاوة عالية ـ تم ترسيب الاغشية

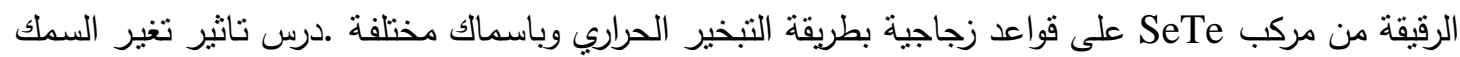

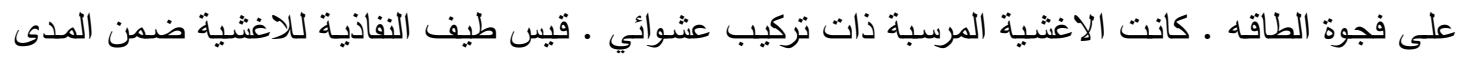

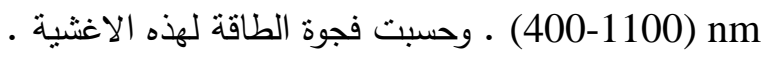

